\title{
Socio-Cultural Impacts of Professional Football Clubs on Local Residents: Developing and Validation of Measurement Scale in Vietnam
}

\author{
${ }^{1}$ Huynh Tri Thien*, ${ }^{1}$ Wanchai Boonrod \\ ${ }^{1}$ Faculty of Sports Science, Chulalongkorn University, Bangkok, Thailand.
}

Submitted 11 June 2019; Accepted in final form 05 August 2019.

\begin{abstract}
Background. Football is the most popular sport in Vietnam, and this is not just a game or sports, it makes a role as nationalism, and football also is viral motivation to push up the development of socio-economic in Vietnam. To date, the majority of existing studies have focused upon the wider economic impacts, with few empirical studies of the social or cultural impacts upon local residents from professional football. Objectives. The paper aims to develop and validate the scale of socio-cultural impacts to examine the perceptions of local residents from professional football clubs in the Socialist Republic of Vietnam. Methods. Before using questionnaire for conducting the scale of socio-cultural impacts to reach participants, structure and content validity of preliminary questionnaire is assessed by a panel of experts with using the test of Item-Objective Congruence. In addition, the reliability test for the draft questionnaire also conducted via the thirty university's students. Data were collected from 1,500 local residents were based on a convenience sample from six cities and provinces of the three regions in Vietnam. After collecting the data, the entire data set was randomly split into two parts for exploratory factor analysis by IBM SPSS version 22.0 and confirmatory factor analysis by LISREL 9.30 in order to confirm the factor structure of the scale of socio-cultural impacts. Results. Results of the exploratory factor analysis identified the four impact factors including three positive socio-cultural impacts as Community Enhancement and Consolidation, Health and Socio-cultural Opportunities, and Economics Benefits; and one negative socio-cultural impacts as Socio-cultural \& Environment Concerns with a total variance of $62.76 \%$. Confirmatory factor analysis showed that after adjusting model, the 4-factor with 37-item model provided a good fit to the data with the index of $\chi 2 / \mathrm{df}=0.343$ with P-value $>0.05$; RMSEA $=0.000 ;$ SRMR $=0.003$; GFI $=1.000$; and AGFI $=0.998$. Conclusion. It is concluded that the Scale of Socio-Cultural Impacts (SSCI) is a valid measuring instrument for assessing perception of local residents on socio-cultural impacts from professional football clubs at their community in Vietnam.
\end{abstract}

KEYWORDS: Football, Community Enhancement, Community Consolidation, Health Opportunities, Sociocultural Opportunities, Economics Benefits

\section{INTRODUCTION}

Football is the most popular sport in Vietnam, and this is not just a game or sports, it makes a role as nationalism, and football also is viral motivation to push up the development of socioeconomic in Vietnam (1). There are many domestic researches said that football is "the king of sport" or "the special religion" in Vietnam (2-
4). In recent, there are more than hundreds of newspapers and television channels put the interest in football on good and bad news. The football news highly affects spectators and fans, so that football is effective tools in order to educate spirit of young people, enhance civic pride and promote national image to international

*. Corresponding Author:

Huynh Tri Thien, $\mathrm{PhD}$

E-mail: huynhtrithien@hotmail.com 
communities (3). To sum up, football could not only exist by themselves but also make the role as "for social community".

After 20 years of development, Vietnam Football League (the V. League) has had many rapidly changes. There were many investors sponsored for the V. League and football clubs with many reasons such as developing football, promoting brand (2), creating networks, etc. As the results, some investors succeed in their football clubs such as Hanoi FC, B. Binh Duong FC, Hoang Anh Gia Lai FC, etc. and there are some investors had to out of the $\mathrm{V}$. League because of some reasons. In addition, soccer is the king of sports as the speech from Mr. Hien Chairman of T\&T Group that owned Hanoi FC that through football, the world can understand more about Vietnam and its people, so it is an effective channel to promote our country (4).

Professional football clubs are not only a tool for economic revitalization, but also the core of the popularity by its identity. Especially, there are a few of professional sport events in Vietnam to attract local residents, especially in local communities. In addition, regional identity gives a football club a deeper meaning (5). There are many factors that make football clubs so important for us, but one of the principal reasons for the popularity of this sport is the identity of the respective clubs. It creates a feeling of belonging and helps to set them apart from other clubs and groups. In this way, clubs pass on their own identity to their supporters. It is the club identity as an individualizing feature that gives the football club its public profile.

The relationship between professional sports and cities is an important public policy issue that has received growing attention in the academic literature. As in many other countries, professional sports - especially football - have enjoyed high and growing levels of attendance, participation, and enthusiasm from the general public (6) in Vietnam. The social importance placed on professional sports is surely disproportionate to their importance in the national economy. Hosting a football club to compete at the professional league has involved diverse participants for generating short- and long-term impacts to local community. According to Morgan, Pritchard and Pride (7), cities want to improve their place reputation by becoming creative destinations. In addition, place or destination brands have to manage complex relationships between brand, image, reputation and identity (8). It is widely known that the professional teams induce both economic benefits and substantial socio-cultural benefits to local community. Although there are possible negative impacts induced from the professional clubs, a high-level demand for investing a professional football club still exists by the authorities (9) and it would include the local team in their urban management plan.

According to study of Knott et al. (10), the socio-cultural impacts of a mega-event are often the most visible, but at the same time the least tangible and measurable. There have been extensive studies of local residents' perception and reaction to the impacts of professional football at European or developed countries. Communities in many rural and urban destinations in Vietnam are affected somewhat by professional football in different ways. Its sociocultural effects in these areas, however, are less well documented, as much of the academic literature concentrates on the impacts in developing countries, especially in rare communist-based-country, or else evaluates them at a more general level. Understanding the sociocultural impacts of professional football clubs on local residents and being able to measure or monitor such impacts is vital to professional sport viability. Advances in knowledge in this area will enable professional football club managers or football match organizers to develop or modify the clubs or the football matches to ensure that they are better aligned to the needs of the host community and at the same time enhance greatly the likely profitability for the professional football clubs.

The main focus of this study aims to develop and validate a new scale for measuring the sociocultural impacts of professional teams to perceptions of local residents through item generation and confirming a newly developed scale for the socio-cultural impacts of professional football clubs to local residents in the Socialist Republic of Vietnam.

Impacts of Professional Football in Vietnam. After 20 years developing the professional league, there are 14 football clubs that are playing at the $\mathrm{V}$. League that from 12 cities or provinces in Vietnam including 7 clubs at Northern region, 2 clubs at Middle region and 5 clubs at Southern region (2), of which 13 are "state owned" clubs that meaning still using some 
kinds of local government's supporting. This has almost led to a state of inertia as many clubs are run like offices and have not evolved with basic issues, such as not responding to emails or phone calls or marketing strategies. Clubs do not see their teams as a "brand" and do very little to promote them or the players.

Professional football clubs in Vietnam are bringing many nuances as well as impacting on the fans as well as local people in a cultural and social aspect in a positive and negative way (3). With professional sports, no fans - football will die. But in the V. League, very few teams have side activities to create interaction between players and fans. As VFF figures show, attendances are on a downward slide with some teams attracting fewer than 1,000 spectators even though the average of spectators were around 7,000 persons per match for three seasons since 2016. Even this ratio was on the top of the professional football leagues in ASEAN, but there were many problems have to solve to make the V. League better, especially the perceptions of local residents or spectators who are the most important issue impacts to the success of the $\mathrm{V}$. League as well as professional football clubs (3).

In addition, the player is simply kicking and leaving, practicing, then competing again, leaving. A boring vicious circle made many teams almost unable to form loyal, stable fans (1). This shows that the operators of professional clubs at the V. League need to have a new look, need to grasp the feelings of the audience, call for the spirit of self-awareness, the spirit of beautiful cheering at everybody. And more importantly, how the quality of the matches must be raised to the satisfaction of the audience, regardless of whether the home team wins or loses (2). These are also the factors that increase positive impacts and limit negative impacts on audiences as well as local people watching the team.

Professional football has attained a dimension that goes far beyond a purely economist view and, as do many other sports, is capable of generating a highly beneficial impact on society. Sports teams feature massive brand values. Leveraging that brand value and using its power for social action therefore has great potential for wide social impact. In addition, professional football has a positive effect on aspects other than economic function, such as education, creation of healthy habits, construction of the community brand and social integration (11).
In addition to the sustainable development of the economic environment that it can generate, a football club also has a social value and a potential to develop the society, especially by forming a local identity and a sense of belonging. Undoubtedly, football also pollutes the environment. The stadium is an artificial structure that destroys part of the natural structure and which uses pretty much energy and other resources. Then, to get to the stadium, spectators use vehicles whose gas emissions deteriorate the quality of the air. During the match, the atmosphere created by the fans in the stands generates noise that pollutes the environment. And at the end of the game, when leaving the stadium, many fans leave their waste after them.

To summarize, the previous studies would investigate perceived social impacts of hosting professional football clubs through dividing into two dimensional structures: positive social impacts and negative social impacts. First, positive social impacts dimension consists of multi-dimensional constructs such as Infrastructure and urban development; Economics benefits; Community consolidation; Socio-cultural exchange; Community visibility \& Image enhancement; and Knowledge \& Health Opportunities. Second, negative social impacts dimension consists of constructs such as Socioeconomics conflicts; Security risks; and Traffic and Environment concerns. According to SQW (12), few events actually monitored their sociocultural impacts to local residents, especially on professional football at the developing countries.

\section{MATERIALS AND METHODS}

Item Generation. This study adopted an interdisciplinary approach emphasized on extensive review of the literature from general event management, tourism, festival and hospitality management, leisure studies, and sport management for building the theoretical framework of the current study. Numerous theories including the social exchange theory and the expectancy-value model of attitude formation were used as a theoretical foundation for this study. Researchers would prepare a comprehensive listing of social-cultural impacts of professional football clubs in order to build initial items.

After developing an initial questionnaire for exploring socio-cultural impacts, structure and content validity of preliminary questionnaire is assessed by a panel of experts. Following panel of 
experts would review revised questionnaire. Experts for this study included five university professors specializing in the sport management discipline and one expert from Vietnam Professional Football League Company which organize professional football in Vietnam. Each panelist is asked to examine the relevance, representativeness, clarity, test format and wording, item content of questionnaire, and other associated sections that have been recommended by previous research (13). Based on feedback from panel of experts, preliminary scale of sociocultural impacts is modified, revised, improved for enhancing structure and content validity. In addition, an evaluation using the index of ItemObjective Congruence (14) is used to test the questionnaire's validity in this research. According to Pongpaew (15), the statements which could be accepted to be the statements included in the sepipilot form of the scale should obtain IOC value between $0.50-1.00$. After the IOC analyzing, there are 70 items in the draft of questionnaire of this study. According to the experts' agreement, the IOC index of each items indicated the accepted and the rejected items. There were 21 items to be adjusted from draft of questionnaire through the IOC index and specialists' recommendation. For the final questionnaire, a total of 49 items including demographics were selected to be included in the final questionnaire.

After the questionnaire is modified, a pilot study is employed to further test through assessing the reliability of the developed scales (16). The pilot study would use convenience samples of undergraduate students from Ton Duc Thang University. A total of 30 questionnaires are collected and purified by using Cronbach's alpha and item-to-total correlations tests in order to assess the reliability of the items. After reliability testing; overall, the Cronbach's alpha reliability of socio-cultural impacts instrument was found at a high of 0.914 that mean reflects good reliability. As finishing initial purification of the questionnaire, the retained items are finally verified through testing on sample of the main study in order to develop a standardized measurement and articulation of the sociocultural impacts.

The initially developed Scale of Socio-cultural Impacts (the SSCI) consisted of two sections: 1) socio-demographic characteristics; and 2) perceptions of local residents on socio-cultural impacts in both positive and negative perspectives, with using a Likert five-point scale was used for every item ranging from "1 = Strongly Disagreed" to "5 = Strongly Agreed" which suitable for currently studying conditions.

Data Collection. Data collection was conducted at six cities and provinces that have famous professional football clubs in V. League 2019 including Ha Noi capital with Ha Noi FC and Nghe An province with Song Lam Nghe An FC at Northern region, Da Nang city with SHB Da Nang FC and Quang Nam province with Quang Nam FC at Middle region, and Gia Lai province with Hoang Anh Gia Lai FC and Ho Chi Minh city with HCMC FC at Southern region.

Because the questionnaires were planned to be collected from Vietnam, additional procedures to translate the questionnaire to Vietnamese were implemented including: (a) forward translation; (b) synthesis; and (c) back translation (17). First, forward translation was conducted by two independent bilingual translators for executing an initial translation of the questionnaire from English to Vietnamese. Then, two independent questionnaires were thoroughly compared by two translators so that they could find out the translation errors (i.e., incorrect wording, using ambiguous terms, etc.). Lastly, the back translation was conducted by newly recruited bilingual graduate students. They were asked to retranslate the questionnaire into the original language, English, so that the researcher could compare the accuracy and equivalence of the translated questionnaire.

The sample was collected through convenience sampling utilizing spatial method based on a sample from only local residents of the hosting community. The current study adopted the recommendation by Hair et al. (18) and Kline (19) to determine appropriate sample size. Based on the recommendation, the target sample size was at least 10 respondents per each observed variable. With respect to this recommendation, this study collected data from a total of 1,500 respondents. Almost local residents were reached at public areas such as football stadiums, Public Park, shopping malls, etc. in order to do survey via the questionnaires. The questionnaire was self-administered and included informed consent form, socio-demographic and the SSCI questions. Thirty-two trained assistant researchers were recruited by the researcher so that they could assist with data collection at the broad areas in the 
hosting communities. Respondents were asked to participate in the survey and spend approximately less than 15 minutes to complete the instrument.

Statistical Analysis. This study was designed to develop a valid and reliable scale to measure perceived social impacts toward hosing largescale sport events from residents' standpoint. Data analyses for retaining the SSCI proceeded into a series of steps. Factor analysis is the main multiple factor analysis techniques adopted to examine community attitudes (20), that focuses on the inter-relationships between a large number of variables and the perceptions of local residents, while the latter attempts to classify people according to their attitudes. After collecting the data, the entire data set was randomly split into two parts as Sample A for EFA - Exploratory factor analysis and Sample B for CFA Confirmatory factor analysis. The dimension reduction (factor) and scale (reliability analysis) procedures from IBM SPSS for Windows (Version 22) and LISREL 9.30 for Windows were utilized in the data analysis. Regarding to EFA, IBM SPSS for Windows was utilized to examine if the data were appropriate for factor analyses, Bartlett's Test of Sphericity (BTS) value and Kaiser-Meyer-Olkin (KMO) measure of sampling adequacy value was evaluated (21). A PAF and identified items were evaluated by the researcher to identify possible factors. Based on the suggested criteria (22-24), the current study identified appropriate factors and items as results. First, the current study used the Kaiser criteria to identify a factor that has an eigenvalue greater than or equal to 1 (22). Second, a factor loading had to be at least equal to or greater than 0.50 in order to be considered as appropriate factors and items. In particular, values between 0.50 and 0.70 are mediocre, values between 0.70 and 0.80 are good, values between 0.80 and 0.90 are great, and values above 0.90 are superb (25). If any item showed less than 0.50 of the factor loading, it would be eliminated. Third, a factor should consist of at least three items in order to become an individual factor $(19,23,26)$. In addition, double-loaded items were deleted for this study. Fourth, the scree plot with the resulting curve was used to determine the factors compared to factor loadings from EFA outputs (27). Lastly, the identified factors and items should be able to be theoretically interpretable for the current study.

Then, concerning to CFA, the LISREL 9.30 program was utilized to conduct estimation, testing goodness-of-fit statistics, and modification of the model. The assessment of model fit was based on the goodness-of-fit index (CFI > 0.95), standardized RMR (SRMR < 0.05), root-mean-square error of approximation $($ RMSEA $<.08)$ and $\chi 2 /$ df ratio $(\chi 2 /$ df ratio $<$ 5.00). Values of the GFI and AGFI also range from zero to 1.00 , with values larger than 0.90 indicating an acceptable fit, and values greater than 0.95 indicating a good fit (28-30). According to previous studies, a very good research model fit is defined as P-value should be higher 0.05 and chi-square/degree of freedom should be smaller than $3.00(18,31)$.

\section{RESULTS}

Of the 1,500 questionnaires served to local residents, 186 questionnaires were discarded due to substantial missing values and reporting of same answers across the all items. Hence, the remaining 1,314 responses were used in actual data analyses for developing and testing measurement statistics of the SSCI with the ration of $87.6 \%$ response.

Descriptive Statistics of Perceived SocioCultural Impacts. All 30 items of positive sociocultural impacts dimension had a mean score greater than 3.50, indicating that participants experienced positive socio-cultural impacts and benefits from having professional football club at their community. On the other hand, of the 11 items for negative socio-cultural impacts dimension, there are three items related the factor of Traffic and Environment concerns had a mean score higher than 2.50, indicating that respondents were not generally experience negative socio-cultural impacts from having professional football club at their community.

Among 6 constructs of positive socio-cultural impacts dimension, Community visibility \& Image enhancement had the highest mean score $(\mathrm{M}=4.35 ; \mathrm{SD}=0.68)$, followed by the Infrastructure \& urban development $(\mathrm{M}=4.34$; $\mathrm{SD}=0.76$ ); and the lowest mean score of positive socio-cultural impacts was Economics benefits $(\mathrm{M}=4.05 ; \mathrm{SD}=0.85)$. In other hands, among 3 constructs of negative socio-cultural impacts dimension, Traffic and Environment concerns had highest mean score $(\mathrm{M}=2.58$; $\mathrm{SD}=1.08)$, followed by Socio-economics conflicts $(\mathrm{M}=$ 2.30; $\mathrm{SD}=1.05$ ); and the lowest mean score of negative socio-cultural impacts was Economics benefits $(\mathrm{M}=2.23$; $\mathrm{SD}=1.12)$. 
Exploratory Factor Analysis for the Scale of Socio-Cultural Impacts. EFAs were conducted using the first data set $(\mathrm{N}=500)$ collected from residents at three regions in Vietnam. The EFA was conducted based on using the 30 items represented positive social impacts and the 11 items represented negative social impacts so that this study could delineate the underlying factor structures. The KMO measure of sampling adequacy value was 0.954 and the BTS was 13118.493 ( $\mathrm{P}<0.001)$ indicating that the sample was appropriate to conduct a factor analysis. As a result of PAF with Varimax rotation, four factors with 37 items were identified, explaining $62.67 \%$ of the total variance.

Three items (ID2, ID3, and KH1) were discarded due to being double loaded to two different factors. Another item (SE4) was discarded because their loadings did not exceed the criteria of 0.50 for this study. Finally, the factor of Infrastructure \& urban development consisting of ID1 was removed because its loading onto a factor did not have appropriate theoretical justification. Then, factor of positive socio-cultural impacts such as Community consolidation and Community visibility \& Image enhancement merged to new factor named Community Enhancement and Consolidation; and factor of Knowledge \& Health Opportunities and Socio-cultural exchange merged to new factor named Health and Socio-cultural Opportunities. In addition, all factor of positive socio-cultural impacts merged to one new factor named Socio-cultural \& Environment Concerns. Therefore, four factors with 37 items emerged for conducting further study. For instance, there were four factors that including three positive socioimpacts factors named Community Enhancement and Consolidation (13 items, $\alpha=0.943$ ), Health and Socio-cultural Opportunities (10 items, $\alpha=$ 0.920), and Economics Benefits ( 3 items, $\alpha=$ 0.823 ); and one negative socio-impacts factor named Socio-cultural and Environment Concerns (11 items, $\alpha=0.942$ ). Overall, the resolved factor structure represented the conceptual SSCI model for the subsequent CFA.

Confirmatory Factor Analysis for the Scale of Socio-Cultural Impacts. The second part of the data set $(n=814)$ was used for conducting a CFA for the residents' perceived social impacts of hosting large-scale sport events. Community Enhancement and Consolidation, Socio-cultural
\& Environment Concerns, Health and Sociocultural Opportunities, and Economics Benefits were the endogenous variables for testing the proposed four-factor model. The LISREL 8.80 program was utilized to conduct estimation, testing goodness-of-fit statistics, and modification of the model.

\begin{tabular}{|c|c|c|c|c|c|c|c|}
\hline Model & $\chi^{2}$ & df & $\chi^{2 / d f}$ & RMSEA & SRMR & GFI & AGFI \\
\hline $\begin{array}{l}2^{\text {nd }} \text { model of } \\
\text { impacts }\end{array}$ & 0.343 & 1 & 0.343 & 0.000 & 0.003 & 1.00 & 0.998 \\
\hline
\end{tabular}

After two times evaluation, as shown in Table 1, the overall fit of the proposed four-factor model appeared to be satisfactory based on the results of various goodness-of-fit statistics. Consequently, a four-factor model with 37 items provided a model fit to the data $(\chi 2=0.343, \mathrm{P}=$ $0.558)$ that $\mathrm{p}$-value higher than .05; and normed chi-square $(\chi 2 / \mathrm{df}=0.343)$ was lower than recommended 3.0 value (26).

In addition, the RMSEA value $=0.000$ indicated that the current model recorded a good fit (29). The SRMR value $=.003$ was less than cut-off value as .08 (Kline, 2005). The GFI value $=1.00$ showed adequate value which was higher than suggested the cut-off point of 0.95 , and the AGFI value $=0.998$ was also greater than the critical value of 0.95 as indicating a good fit for the model complexity (29).

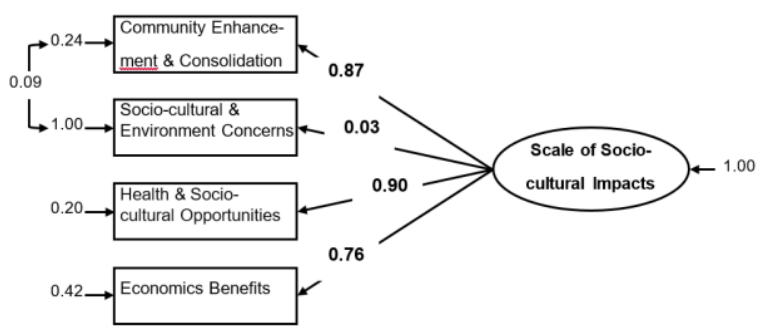

Figure 1. The Second Evaluation for the Model of Sociocultural Impacts

For the other index from $2^{\text {nd }} \mathrm{CFA}$ evaluation, the $\beta$-value of three factors including the highest factor of Community Enhancement \& Consolidation had value of 0.557 ; next to factor of Economics Benefits had value of 0.661, and factor of Health \& Socio-cultural Opportunities had value of 0.690 ; all these positive sociocultural impacts factors that were higher than the cut-off value of 0.70 (32); however, the $\beta$-value of the last factor of Socio-cultural and Environment Concerns had value of 0.028 that 
also accepted because this factor is the negative socio-cultural impacts. In addition, the t-value of four factors from the scale of socio-cultural impacts also the same trends as the $\beta$-value. To be more detailed, the t-value of three factors including Community Enhancement \& Consolidation, Health \& Socio-cultural Opportunities and Economics Benefits were significant with value less than .05; except Sociocultural \& Environment Concerns was not significant with value higher than 0.05 .

Last but not least, the result indicated that all inter-factor loadings were sufficiently below the recommended threshold of 0.85 by Kline (19), that was ranging from 0.01 (Economics Benefits and Socio-cultural \& Environment Concerns) to 0.78 (Health \& Socio-cultural Opportunities and Community Enhancement \& Consolidation). Almost the factors had statistically significant correlations except two correlations among SEC - Socio-cultural \& Environment Concerns vs HSO - Health \& Socio-cultural Opportunities (correlation value $=0.03, \mathrm{P}$ value $>0.01)$ and $\mathrm{SEC}$ - Socio-cultural \& Environment Concerns vs ECB-Economics Benefits (correlation value = 0.01 , $\mathrm{P}$ value $>0.01$ ) did not result in statistically significant relationships. These results could be interpreted that respondents might have substantially different attitudes toward the negative socio-cultural impacts of professional football clubs to local residents.

\section{DISCUSSION}

After 20 years for developing football in Vietnam, having a professional football club at city/province has been recognized as an important component to bring economics, socio-cultural and political benefits to local community. Firstly, the results of this study partially validated for the Scale of Socio-Cultural Impacts (SSCI) which using to measure the impacts of professional football clubs to local residents. Then, the results of study also supported this belief as the participants perceived positively that the professional football clubs would bring the positive socio-cultural impacts to local communities in Vietnam.

Findings of the descriptive statistics indicated that the overall mean score of positive sociocultural impacts dimension was 4.17 , while the mean score of negative socio-cultural impacts dimension was 2.38; that means the local residents believe that professional football clubs create more socio-cultural benefits than the socio- cultural costs. This finding indicates that the local residents do not see professional football clubs as activities that create socio-cultural problems within the community. This finding has the same results from previous studies that positive social impacts of sport events such as community visibility, image enhancement, knowledge and entertainment opportunity, etc. are more important benefits compared to positive economic impacts $(33,34)$. One explanation for this might be the important of football in Vietnam society (35). There were many researches said that football is "the king of sport" or "the special religion" in Vietnam (2-4). In addition, as the speech from Mr. Hien - Chairman of T\&T Group that owned Hanoi FC - that through soccer, the world can understand more about Vietnam and its people, so it is an effective channel to promote our country (4).

\section{CONCLUSION}

From the literature, nine factors of sociocultural impacts from professional football club to local residents were identified. The proposed measurement instrument was tested by exploratory and confirmatory factor analysis using the data gathered from the local residents at the cities/provinces that have professional football clubs. Results confirmed the four factors of socio-cultural impacts of professional football clubs to residents including Community Enhancement \& Consolidation, Socio-cultural \& Environment Concerns, Health \& Socio-cultural Opportunities, and Economics Benefits. The final proposed instrument utilized 37 items to measure the four factors of socio-cultural impacts of professional football clubs to residents on local communities. All of the reliability and validity scores were above acceptable levels. Overall, after analyzing EFA and CFA, it is concluded that the SSCI is a valid measuring instrument for assessing socio-cultural impacts perceptions of local residents who having a professional football clubs at the community, especially in the Socialist Republic of Vietnam.

\section{Limitations and Future Research}

This study strived to develop a valid and reliable instrument for measuring perceptions of local residents from socio-cultural impacts of professional football clubs at the community. However, this study contains a number of limitations due to the research design and procedures. Firstly, the sample participants of this 
study have reached at public areas including in front of stadium with random methods would not be appropriate to be generalized to other contexts and populations. According to Waitt (36), perceived social impacts and assessment of exchanged value are likely to be different across socio-demographic characteristics; thus, the results of the current study may not be generalized to other events and populations. For future research, it would be valuable to assess a variety of contexts (i.e., mega-sport events, community sport events, etc.) in order to provide managerial insight for sport marketers based on comprehensive understanding of residents' affirmative attitudes.

Secondly, the initial nine factors were deemed to be utilized to assess socio-cultural impacts of professional football club to local residents, only four factors were retained. This might be the reason that this study relied heavily on statistical procedures in order to purify and reduce the dimensions of the SSCI. Several factors were discarded due to ambiguous factor justification (i.e., similarity and lack of theoretical justification). Therefore, future studies should be conducted for revision of conceptual frameworks and factor development in order to provide a more clear and constant structure of psychometric construct of socio-cultural impacts.

Lastly, although the four-factor model did show improved model fit, the reliability issues can be a crucial factor for implementing the SSCI to other events and populations. Therefore, future research should be emphasized on exploring more comprehensive constructs regarding sociocultural impacts including security risks, sustainability issues, and also various sociopsychological benefits (i.e., political impacts, sport-specific outcome, etc.).

\section{APPLICABLE REMARKS}

- This finding should encourage the professional football clubs to strengthen ties with the local residents to ensure that they are develop their positive perceptions on socio-cultural impacts of the clubs as well as decrease their negative perceptions on socio-cultural impacts of the clubs.

- It is important for professional football club's managers to deeply understand and response to enhance the perceptions of local residents and/or spectators to let the professional football club develop sustainably.

- Regarding the valid and reliable scale for measuring the socio-cultural impacts of professional football clubs to local residents, it is suggested for the football league's managers and/or executives; football club's managers and marketers; and local governments on department of sports to employ this instrument to assess and receive useful information from local residents for improve the developing strategies for professional football in Vietnam.

\section{REFERENCES}

1. Sommerville S. Vietnamese Football: An in-depth Analysis 2017 [updated 2018; cited 2019]. Available from: http://inbedwithmaradona.com/journal/2017/6/5/vietnamese-football-an-in-depth-analysis.

2. Duong NC. The establishment of the professional football in Vietnam 2017 [cited 2019 2019]. Available from: http://www.vkhtdtt.vn/tin-tuc-the-thao-quoc/ArtMID/434/ArticleID/4116/Sự-ra-đời-B243ngđ225-chuy234n-nghiệp-Việt-Nam.

3. Pham NV. Situations of professional football in Vietnam: Vietnam Sports Administration: Sport Science Magazines; 2017.

4. Quoc D. Building a soccer culture from scratch: Chairman of T\&T Group. Vietnam: The Leader 2018 [cited 2019 2019]. Available from: https://e.theleader.vn/building-a-soccer-culture-from-scratchchairman-of-tt-group-1543811557213.htm.

5. Gómez-Bantel A. Football clubs as symbols of regional identities. Soccer Soc. 2015;17(5):692-702. doi: 10.1080/14660970.2015.1100430

6. Duerden J. Vietnam football's reaping rewards from investments in youth development 2017 [cited 2019 2018]. Available from: https://www.todayonline.com/sports/vietnam-footballs-reaping-rewardsinvestments-youth-development.

7. Morgan N, Pritchard A, Pride R. Destination brands: Managing place reputation: Routledge; 2011.

8. Morgan N. Time for 'mindful' destination management and marketing. J Destinat Market Manag. 2012;1(1-2):8-9. doi: 10.1016/j.jdmm.2012.07.003 
9. Sparvero E, Chalip L. Professional Teams as Leverageable Assets: Strategic Creation of Community Value. Sport Manag Rev. 2007;10(1):1-30. doi: 10.1016/s1441-3523(07)70001-3

10. Knott B, Swart K, Visser S. The impact of sport mega-events on the quality of life for host city residents: reflections on the 2010 FIFA World Cup. 2015 2223-814X.

11. Chalkley-Rhoden S. Decline of women's sports coverage in Australia 'a tragedy': report shows drop in coverage 2015. Available from: http://www.abc.net.au/news/2015-04-12/decline-of-women-sportscoverage-in-australia-a-tragedy/6359786.

12. SQW. Culture 10 evaluation final report. Leeds: SQW Consultants; 2006.

13. Babbie E. The practice of social research. New York: Macmillan; 1992.

14. Rovinelli RJ, Hambleton RK. On the use of content specialists in the assessment of criterion-referenced test item validity. Dutch J Edu Res. 1976;2(1):49-60.

15. Pongpaew T. Educational Research. Mahasarakhram: Mahasarakhram University; 2009.

16. Ary D, Jocobs LC, Razavieh A, Corensen C. Introduction to research in education. Belmont, CA: Thomson Higher Education; 2006.

17. Su CT, Parham LD. Generating a valid questionnaire translation for cross-cultural use. Am J Occup Ther. 2002;56(5):581-585. doi: 10.5014/ajot.56.5.581 pmid: 12269514

18. Hair JF, Black WC, Babin BJ, Anderson RE, Tatham RL. Multivariate data analysis. Upper Saddle River, NJ: Prentice Hall; 2006.

19. Kline RB. Principles and practice of structural equation modeling. New York, NY: Guilford; 2005.

20. Andriotis K, Vaughan RD. Urban Residents' Attitudes toward Tourism Development: The Case of Crete. J Travel Res. 2016;42(2):172-185. doi: 10.1177/0047287503257488

21. Kaiser HF. An index of factorial simplicity. Psychometrika. 1974;39(1):31-36. doi: 10.1007/bf02291575

22. Andrew DPS, Pederson PM, McEvoy CD. Research methods and design in sport management. Champaign, IL: Human Kinetics; 2011.

23. Meyers LS, Gamst G, Guarino AJ. Applied multivariate research: Design and interpretation. Thousand Oaks, CA: Sage Publications; 2005.

24. Schumacker RE, Lomax RG. A beginner's guide to structural equation modeling. New York, NY: Routledge; 2010.

25. Hutcheson G, Sofroniou N. The multivariate social scientist: Introductory statistics using generalized linear models. Thousand Oaks, CA: Sage; 1999.

26. Bollen KA. Structural equations with latent variables. New York, NY: John Wiley \& Sons; 1989.

27. Cattell RB. The Scree Test For The Number Of Factors. Multivariate Behav Res. 1966;1(2):245-276. doi: 10.1207/s15327906mbr0102_10 pmid: 26828106

28. Bentler PM. Comparative fit indexes in structural models. Psychol Bull. 1990;107(2):238-246. pmid: 2320703

29. Hu Lt, Bentler PM. Cutoff criteria for fit indexes in covariance structure analysis: Conventional criteria versus new alternatives. Struct Equation Model Multidisciplin J. 1999;6(1):1-55. doi: 10.1080/10705519909540118

30. Steiger JH. Structural Model Evaluation and Modification: An Interval Estimation Approach. Multivariate Behav Res. 1990;25(2):173-180. doi: 10.1207/s15327906mbr2502_4 pmid: 26794479

31. Reisinger Y, Turner L. Structural equation modeling with Lisrel: application in tourism. Tourism Manage. 1999;20(1):71-88. doi: 10.1016/s0261-5177(98)00104-6

32. Anderson JC, Gerbing DW. Structural equation modeling in practice: A review and recommended twostep approach. Psycholo Bull. 1988;103(3):411-423. doi: 10.1037/0033-2909.103.3.411

33. Mihalik BJ, Cummings P, editors. Host perceptions of the 1996 Atlanta Olympics: Support, attendance, benefits and liabilities. Travel and tourism research association 26th annual proceedings; 1995.

34. Ritchie JRB, Aitken CE. Olympulse II - Evolving Resident Attitudes Toward the 1988 Olympic Winter Games. J Travel Res. 2016;23(3):28-33. doi: 10.1177/004728758502300306

35. Tomiyama A. Historic soccer run brings unequal Vietnam together. Japan: Nikkei Asian Review 2018 [cited 2019 2018]. Available from: https://asia.nikkei.com/Location/Southeast-Asia/Vietnam/Historicsoccer-run-brings-unequal-Vietnam-together.

36. Waitt G. Social impacts of the Sydney Olympics. Annals of Tourism Research. 2003;30(1):194-215. doi: 10.1016/s0160-7383(02)00050-6 